\title{
More than Color: Pigments with Thermal Storage Capacity; Processing and Degradation Behavior
}

\author{
Estibaliz Aranzabe ${ }^{*}$, Pedro María Villasante2, Ricard March ${ }^{2}$, María Isabel Arriortua ${ }^{3 *}$, \\ Aitor Larrañaga ${ }^{3}$, Ana Aranzabe ${ }^{1}$ \\ ${ }^{1}$ IK4-Tekniker, Eibar, Spain \\ ${ }^{2}$ Nubiola Pigmentos S.L., Laudio, Spain \\ ${ }^{3}$ Facultad de Ciencia y Tecnología, Universidad del País Vasco (UPV/EHU), Leioa, Spain \\ Email: ${ }^{*}$ estibaliz.aranzabe@tekniker.es, ${ }^{*}$ maribel.arriortua@ehu.es
}

Received 17 April 2015; accepted 18 May 2015; published 20 May 2015

Copyright (C) 2015 by authors and Scientific Research Publishing Inc.

This work is licensed under the Creative Commons Attribution International License (CC BY). http://creativecommons.org/licenses/by/4.0/

(c) (i) Open Access

\section{Abstract}

A standard ultramarine pigment was used to produce phase change material composites, by adsorbing n-hexadecane paraffin around the pigment surface with the aim of obtaining a pigment providing thermal storage capacity apart from color. Vacuum impregnation method was employed optimizing the process variables to maximize the latent heat of the hexadecane/pigment composite. In addition to the process optimization, the stability of the composite having the maximum latent heat was investigated. The hexadecane/pigment composite providing the highest latent heat has a Latent heat of fusion of $44 \mathrm{~J} / \mathrm{g}$ (around a $20 \% \mathrm{wt}$. hexadecane adsorbed in the pigment). Durability of the material was tested by thermo-diffractometric measurements. The results indicate slow reduction of the area intensity up to $6.5 \%$ after the 100 cycles.

\section{Keywords}

Ultramarine Blue, Hexadecane, Phase Change Material, Thermal Storage

\section{Introduction}

Phase change materials (PCM) have the ability to store a large amount of latent heat within the temperature range associated with a phase change as they have a high enthalpy of fusion in a small volume [1].

PCM integrated building components could have a high potential because of their ability to reduce energy

${ }^{*}$ Corresponding authors.

How to cite this paper: Aranzabe, E., Villasante, P.M., March, R., Arriortua, M.I., Larrañaga, A. and Aranzabe, A. (2015) More than Color: Pigments with Thermal Storage Capacity; Processing and Degradation Behavior. Advances in Materials Physics and Chemistry, 5, 171-184. http://dx.doi.org/10.4236/ampc.2015.55018 
consumption for space conditioning and reduce peak loads while improving occupant comfort [2]. Among all the PCM applications, the PCM integration in wallboards, roof \& ceiling, and windows has been deeply studied, due to its relatively easy implementation and more effective heat exchange area [3].

Materials used as PCMs can be divided into different subcategories based on their chemical composition: organic compounds, inorganic compounds and eutectic mixtures. However, among these materials, paraffin is believed to be the most promising phase change material because is stable, non-toxic and not corrosive; it has a large latent heat and low cost [4]-[8].

The thermal energy of paraffin is transferred when the material changes from a solid to a liquid or a liquid to a solid, being necessary to contain it to prevent leakages. The most promising methods reported for the incorporation of PCMs in the construction materials are: direct incorporation, immersion and encapsulation. Some researchers pointed out that the direct incorporation and the immersion methods could cause a leakage problem which is not good for long-term use [9].

Depending on the capsule size, the encapsulated PCMs are classified in macro or micro-encapsulated, and there are a wide variety of encapsulating methods and systems obtaining different sizes, geometries and materials [10] [11]. With macro-encapsulated PCMs, the leakage problem can be avoided but it has the disadvantage of poor thermal conductivity and the complicated integration to the building materials. Micro-encapsulated PCMs have been used in thermal energy storage of buildings being much easier to incorporate the microencapsulated PCMs into construction materials [12] [13]. However, this material has two main drawbacks: it is a noneconomical technique and there is low thermal conductivity through the capsule [13].

In contrast, a porous material/phase change composite is attractive since it need not be encapsulated, provides no corrosion and enables quick heat transfer [14]. Then support of PCMs into porous materials is a promising alternative method for the encapsulation of PCMs [15]-[17] but there is still a real need of development concerning PCM containment method to be economically available [5].

However, the storage materials and containers have insufficient long term stability and this has limited the use of latent heat stores. This poor stability is mainly due to the poor stability of the materials properties due to thermal cycling.

Ultramarine blue pigment (UB) is an ancient inorganic pigment manufactured by the burning of sodium sulfate, quartz, and sulfur round $800^{\circ} \mathrm{C}$, which produces a sodium aluminum silicate sulfide structure $\left(\mathrm{Na}_{8} \mathrm{Al}_{6} \mathrm{Si}_{6} \mathrm{O}_{24} \mathrm{~S}_{2}\right)$ similar to Sodalite [18]. Taking into account that ultramarine blue are a family of low-cost mineral pigments with high pigmentary properties and commonly used in construction sector (concrete, paints, polymers), the aim of this study is to develop a form-stable phase change material composites based on ultramarine blue as the supporting matrix and n-hexadecane as the PCM. Vacuum impregnation method has been proposed for obtaining a pigment with thermal storage capabilities. The main advantage of the use of this hexadecane/pigment composite is that manufacturing processes of building components would not be altered as the pigment gives itself the pursued thermal storage capability apart from giving the color to the component.

Durability of the hexadecane/pigment composite against temperature has been demonstrated by analyzing the latent heat of the composite after subjecting it to $30^{\circ} \mathrm{C}$ during 1000 hours. To evaluate the reliability of PCMs during phase-change process, commonly, hundred loops of heating-cooling dynamic DSC scans are normally performed in a sealed pan reducing the amount of PCM lost by vaporization but not simulating real-life conditions.

In this work, long-term stability (cycling without any material degradation) has been tested by thermo-diffractometric cyclic measurements in static air. Given that the crystal signal of the n-hexadecane could be monitored by using X-ray diffraction, 100 cycles of heating and cooling were performed and the area intensity of the crystals was monitored.

\section{Materials}

\subsection{Ultramarine Pigment}

A standard ultramarine blue pigment produced by Nubiola Pigmentos S.L. was used. Ultramarine pigment compositions are based on the crystal chemistry of the royal blue Sodalite mineral Lazurite

$\left[\mathrm{Na}_{6} \mathrm{Ca}_{2} \mathrm{Al}_{6} \mathrm{Si}_{6} \mathrm{O}_{24}\left(\mathrm{~S}_{\mathrm{n}}, \mathrm{SO}_{4}\right)_{2}\right]$.

Some compositions suggested for synthetic ultramarine blue pigments include $\mathrm{Na}_{8} \mathrm{Al}_{6} \mathrm{Si}_{6} \mathrm{O}_{24} \mathrm{~S}_{4}$ or

$\mathrm{Na}_{7} \mathrm{Al}_{6} \mathrm{Si}_{6} \mathrm{O}_{24} \mathrm{~S}_{3}$ [19], although actual compositions are usually complicated by minor amounts of impurities 
from starting materials.

The elemental analysis with X-ray fluorescence (XRF) of the pigment was carried out in a Bruker S8 Tiger 4 $\mathrm{K}$ spectrometer working at $4 \mathrm{Kw}$ and up to $60 \mathrm{Kv}$ and $170 \mathrm{~mA}$. 200 bar pigment pressed powder pellet were analyzed under vacuum conditions using customized calibrated Quant-Express program. Table 1 shows the XRF results for the selected ultramarine blue pigment considering main elements in contrast with the nominal values for two ideal compositions.

The particle size distribution (0.02 to $2000 \mu \mathrm{m}$ range) of the pigment was analyzed using a Malvern Mastersizer 2000 after keeping the sample in ultrasonic agitation for $2 \mathrm{~min}$. Water was used as the dispersion media and a particle Refractive Index of 1.510 was considered for the measurement. The sample and background measurement times were fixed in 10 seconds and 5 cycles of measurement were done using a delay time between measurements of 5 seconds (Figure 1).

For the results calculation, a general purpose model was selected. Figure 1 shows the particle volume distribution and cumulative volume of the sample. The volume distribution shows the particles in a given size range by percentage of the total sample volume, while the cumulative volume curve tracks the total volume of all size ranges as they approach $100 \%$. A stable and mono-modal distribution was obtained for this system being the main particle size $\mathrm{d}_{50}$ of $1.2 \mu \mathrm{m}$.

The scanning electron microscope (SEM) micrograph was recorded with Hitachi S-4800 equipment using Secondary Electron Detector at $3 \mathrm{kV}$ accelerating voltage and $8 \mathrm{~mm}$ working distance (Figure 2). It indicates rather irregular shape of the pigment particles. The size of the particles is mostly in range $\sim 1-2 \mu \mathrm{m}$ in good agreement with the particle size distribution results.

The crystal structure of the pigment was analyzed by X-ray diffraction (XRD). The X-ray powder diffraction patterns were collected by using a PHILIPS X'PERT PRO automatic diffractometer operating at $40 \mathrm{kV}$ and 40 $\mathrm{mA}$, in theta-theta configuration, secondary monochromator with $\mathrm{Cu}-\mathrm{K} \alpha$ radiation $(\lambda=1.5418 \AA)$ and a PIXcel solid state detector (active length in $2 \theta 3.347^{\circ}$ ). Data were collected from $10^{\circ}$ to $80^{\circ} 2 \theta$ (step size $=0.02606$ and time per step $=500 \mathrm{~s}$ ) at RT. A fixed divergence and antiscattering slit giving a constant volume of sample illumination were used.

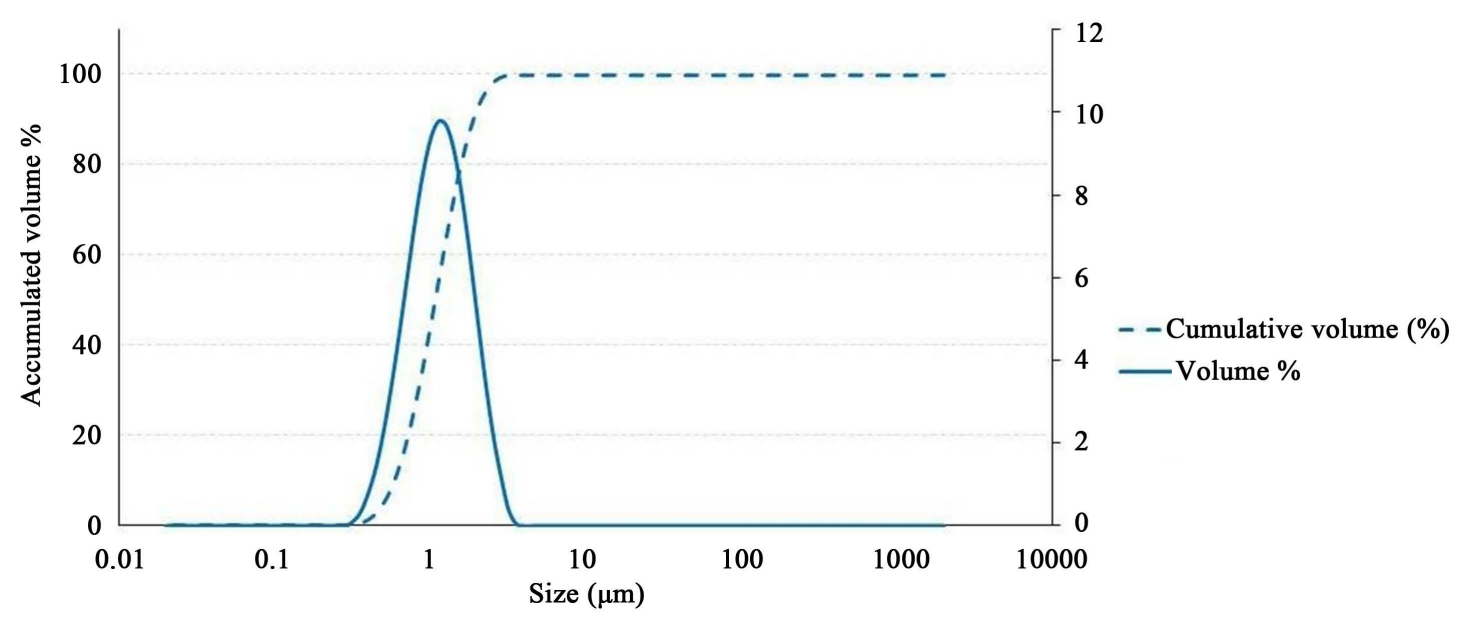

Figure 1. Particle size distribution of the standard ultramarine blue pigment in water.

Table 1. XRF results for the selected ultramarine blue pigment.

\begin{tabular}{cccccccc}
\hline Element \% & $\mathrm{Si}$ & $\mathrm{Al}$ & $\mathrm{Na}$ & $\mathrm{S}$ & $\mathrm{O}$ & 38.1 & 1.3 \\
$\mathrm{XRF}$ & 18.7 & 13.5 & 16.1 & 12.3 & 12.5 & 37.4 \\
$\mathrm{Na}_{8} \mathrm{Al}_{6} \mathrm{Si}_{6} \mathrm{O}_{24} \mathrm{~S}_{4}$ & 16.4 & 15.8 & 17.9 & 16.6 & 9.9 & -0.1 \\
$\mathrm{Na}_{7} \mathrm{Al}_{6} \mathrm{Si}_{6} \mathrm{O}_{24} \mathrm{~S}_{3}$ & 17.4 & 16.7 & 1 & 39.5 \\
\hline
\end{tabular}

Error $\pm 0.1 \%$. Bal $=$ Balance. 


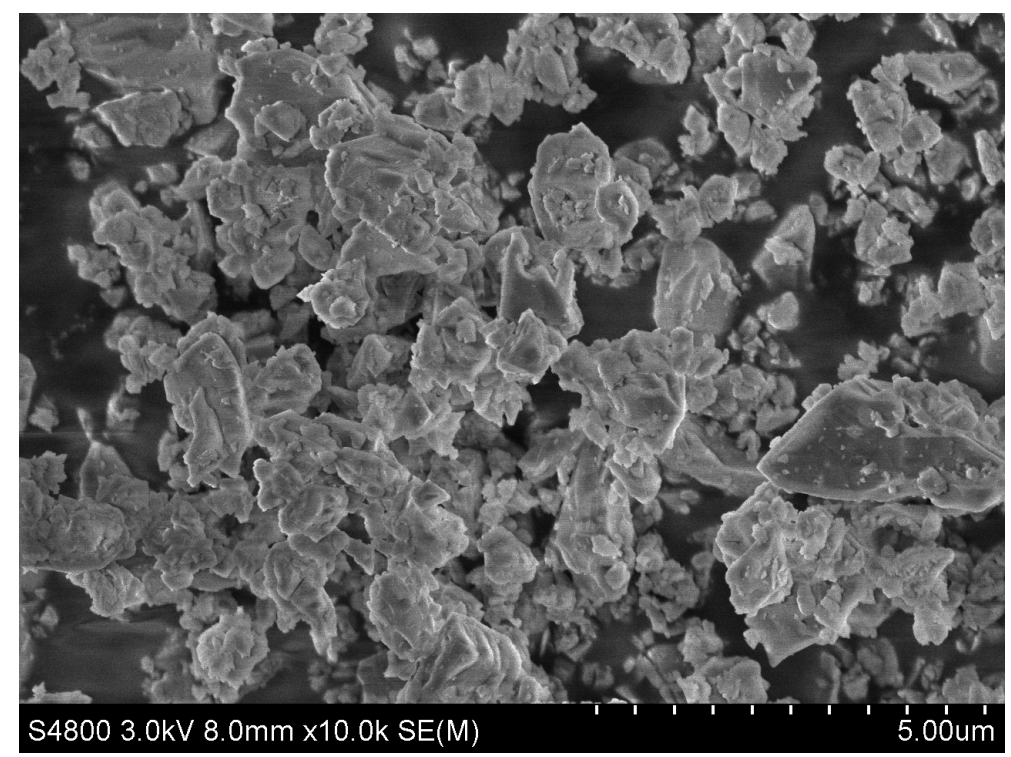

Figure 2. SEM micrographs of standard ultramarine blue pigment.

Preliminary identification of the initial phases was evaluated using the Powder Diffraction File (PDF) database. PANalytical X'Pert High Score program was used for identification and Miller indexing of all observed maxima. XRD data were in good agreement with Sodalite "Pigment Blue" (00-046-0103) and small impurities of Sodium Sulfide (00-003-0933) and Sodium Hydrogen Sulfide (01-077-1883) (Figure 3).

The deconvolution of the principal diffraction maxima using the peak-fit option of the WinPLOTR program without structural model was used to calculate the broadening of the diffraction line for the $24.23^{\circ} 2 \theta$ peak position of the pigment (Figure 4). The average size of the crystalline domains (coherently diffracting domains) of the sample was extracted from the broadening of the signal using the Scherrer equation [20]:

$$
\beta_{h k l}=k \cdot \lambda / L_{h k l} \cdot \cos \theta
$$

where $\beta_{h k l}$ is the broadening of the diffraction line measured at half the line maximum intensity (FWHM) taking in to account instrumental contribution $\left(\beta I n s t=0.1^{\circ}\right), \lambda$ is the X-ray wavelength, $L_{h k l}$ is the crystal size and $\theta$ is the diffraction angle. $K$ is the Scherrer shape factor ( $K=0.9$ was used for the calculations). The shape factor provides information about the "roundness" of the particle, being $k=1$ for spherical particle and $k<1$ for the rest of particles. The calculated crystallite sizes are 80(5) $\mathrm{nm}$.

The diffraction data of the samples were fitted using the FULLPROF program [21]-[23]. In the initial profile refinement the unit cell parameters, peak shape (pseudo-Voigt), background, systematic $2 \theta$ shift, overall isotropic displacement, U,V,W half-width parameters for the profile function and asymmetry parameters were calculated (Figure 5).

The observed impurities and their semi quantitative analysis obtained from the refinement are $\mathrm{Na} 2 \mathrm{~S}$ ( $\sim 2 \%$ in weight) and Na S H ( 3\% in weight).

The obtained results show a good agreement between the experimental and calculated data, the final reliability factors, are Rp: 8.16, Rwp: 11.6, Chi2: 6.82 and Bragg R-factor: 0.778.

\section{2. $\mathrm{n}$-Hexadecane}

Laboratory grade hexadecane $\left(\mathrm{C}_{16} \mathrm{H}_{34}\right)$ (Scharlab, 99\%) was used as received. A Differential Scanning Calorimetry measurement was carried out using a DSC (Mettler Toledo HP DSC827) with the aim of obtaining quantitative data on melting and crystallization point as well as latent heat of fusion and crystallization of hexadecane. The DSC measurements were carried out under nitrogen atmosphere $(50 \mathrm{ml} / \mathrm{min})$, using around $5 \mathrm{mg}$ as a sample weight in a sealed aluminum pan. Heating rate and precision of temperature were $5^{\circ} \mathrm{C} / \mathrm{min}$ and $\pm 0.01^{\circ} \mathrm{C}$, respectively. A dynamic method was used with a temperature ranged from $-10^{\circ} \mathrm{C}$ to $50^{\circ} \mathrm{C}$ at a rate of $5^{\circ} \mathrm{C} / \mathrm{min}$ (Figure 6). 


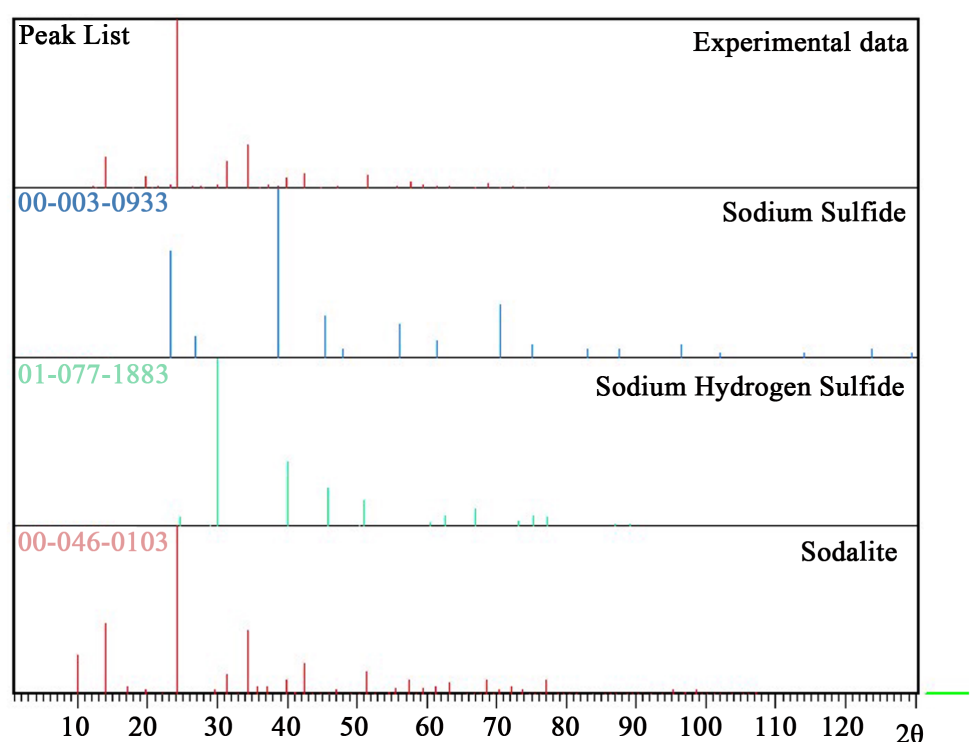

Figure 3. Phase identification of the X-ray powder diffraction pattern of the original sample.

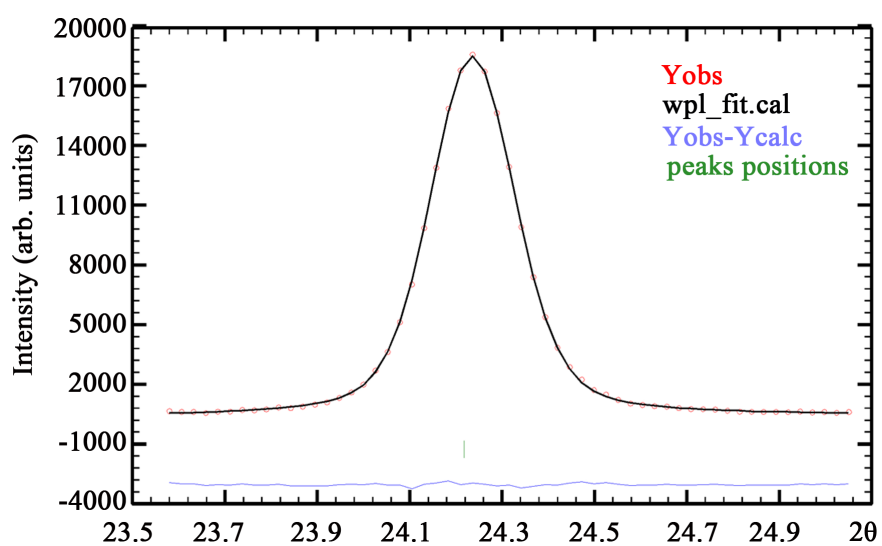

Figure 4. Deconvolution of the X-ray powder diffraction (211) maxima of Sodalite.

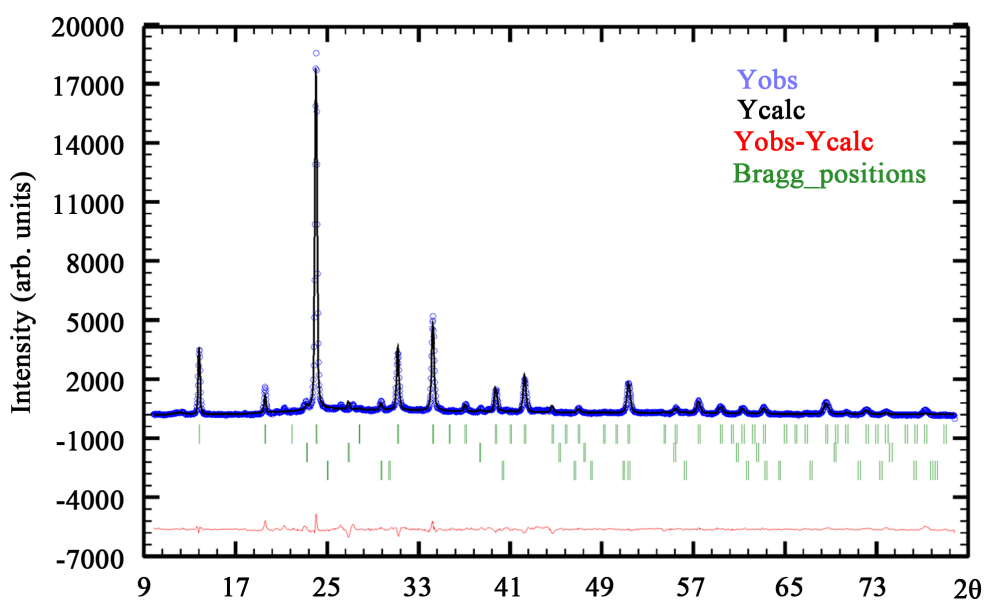

Figure 5. X-ray diffraction full profile refinement. Circles denote experimental points; upper solid lines are calculated profiles. Theoretical peak positions (vertical sticks) and difference lines are shown in the bottom of each pattern. 


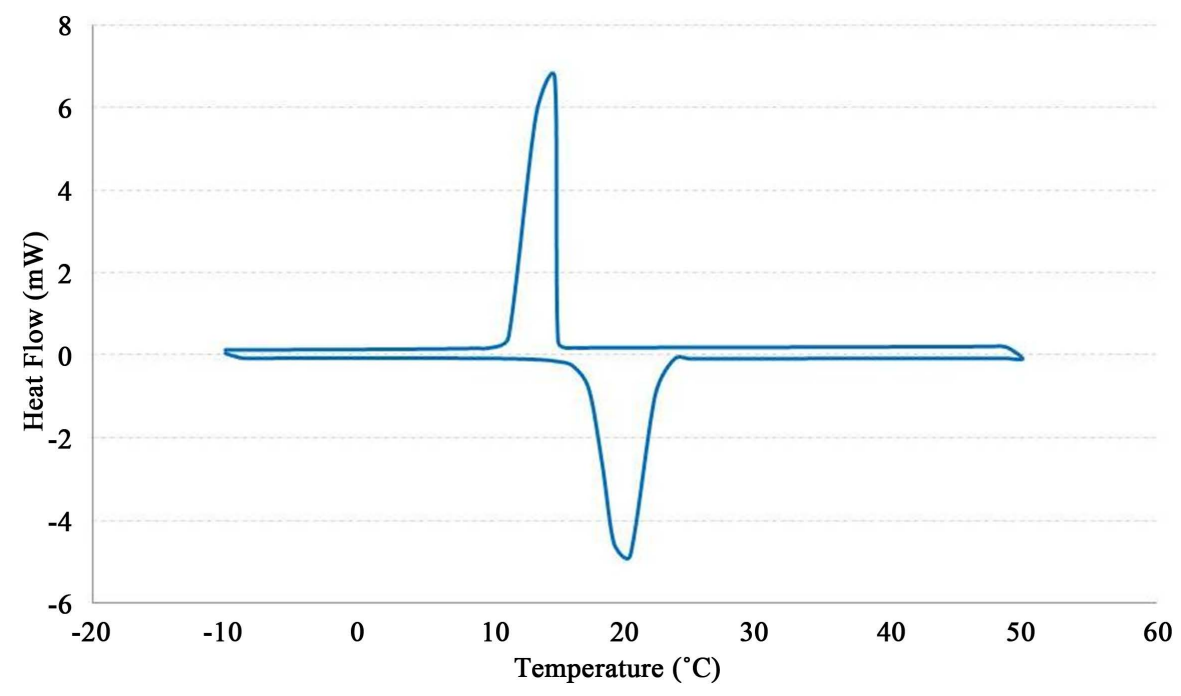

Figure 6. n-hexadecane Differential Scanning Calorimetry Analysis.

Table 2 presents the thermal properties of hexadecane obtained from DSC analysis. The phase change temperature corresponds with the onset temperatures obtained by drawing a line at the point of maximum slope of the leading edge of the DSC peak and extrapolating baseline on the same side as the leading edge of the peak. The latent heat of phase change was calculated by numerical integration of the area under the peaks. The reproducibility of measurements was assessed by two measurements.

The X-ray diffraction (XRD) patterns for the hexadecane were collected on a Bruker D8 Advance diffractometer operating at $30 \mathrm{kV}$ and $20 \mathrm{~mA}$, equipped with a Cu tube $(\lambda=1.5418 \AA$ ), a Vantec-1 PSD detector, and an Anton Parr MRI low-temperature camera. The powder patterns were recorded in $2 \theta$ steps of $0.033^{\circ}$ in the $5 \leq 2 \theta$ $\leq 40$ range, counting for $0.8 \mathrm{~s}$ per step. Data sets were recorded from $8^{\circ} \mathrm{C}$ to $34^{\circ} \mathrm{C}$ every $2^{\circ} \mathrm{C}$, with a $0.16^{\circ} \mathrm{C} \cdot \mathrm{s}^{-1}$ heating rate between temperatures.

The obtained results show the transformation from crystalline to amorphous of hexadecane (PDF 00-0301745) at temperatures near $18^{\circ} \mathrm{C}$ (Figure 7).

The average size of the coherently diffracting domain extracted from the broadening of the (013) signal using the Scherrer equation was around $230 \mathrm{~nm}$.

\section{Fabrication of the Pigment with Thermal Storage Capability}

Vacuum impregnation method was employed for the fabrication of the form-stable phase change materials for thermal energy storage.

\subsection{Processing}

Hexadecane/pigment composite was fabricated by using vacuum impregnation method. The pigment was placed inside a flask connected to a vacuum pump, a vacuum meter and a funnel containing the liquid hexadecane. After having the pigment under 40 mbar of pressure during a certain time in order to evacuate existing air from the pigment pores, the liquid hexadecane was added. After having the mixture pigment-hexadecane under vacuum, the vacuum pump was turned off to force the liquid hexadecane to be adsorbed around the ceramic pigment surface (see process in Figure 8).

Different experiments were planned to optimize five different process variables with the aim of obtaining a composite with the maximum latent heat:

a) ratio pigment: hexadecane,

b) cleaning strategies,

c) the time having the pigment under vacuum,

d) the time having the mixture pigment-hexadecane under vacuum,

e) the time having the pigment-hexadecane mixture at atmospheric pressure 


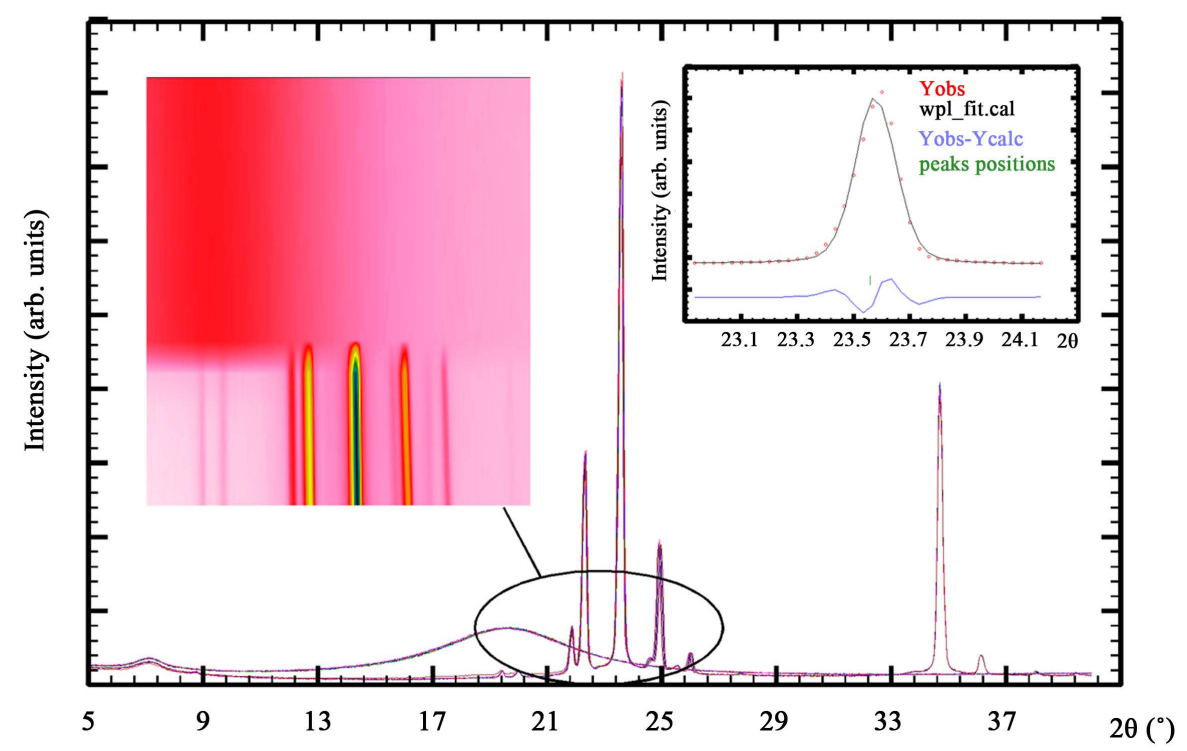

Figure 7. Phase crystallization behavior at low temperature.
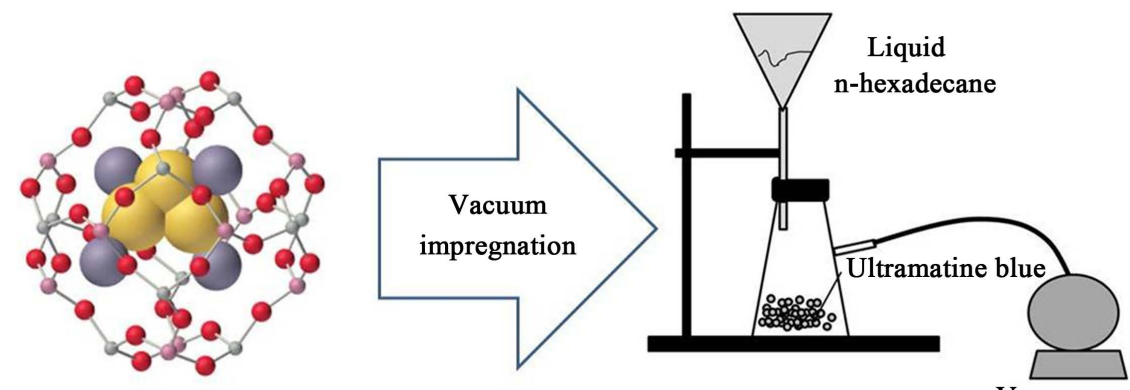

1-Pigment under vacuum

2-Pigment + liquid PCM under

vacuum

3-Pigment + liquid PCM at

atmospheric pressure

4-Washing

5-Drying at $60^{\circ} \mathrm{C}$ during 1 hour

Vacuum pump

Figure 8. Vacuum impregnation process description.

Table 2. Thermal properties of n-hexadecane.

\begin{tabular}{cc}
\hline Property & Value \\
\hline Melting point $\left({ }^{\circ} \mathrm{C}\right)$ & 17.66 \\
Melting point peak $\left({ }^{\circ} \mathrm{C}\right)$ & 19.11 \\
Melting end point $\left({ }^{\circ} \mathrm{C}\right)$ & 20.66 \\
Heat of fusion (melting) $(\mathrm{J} / \mathrm{g})$ & 217 \\
Crystallization point $\left({ }^{\circ} \mathrm{C}\right)$ & 16.15 \\
Crystallization point peak $\left({ }^{\circ} \mathrm{C}\right)$ & 15.85 \\
Crystallization end point $\left({ }^{\circ} \mathrm{C}\right)$ & 14.31 \\
Heat of fusion (crystallization) $(\mathrm{J} / \mathrm{g})$ & 224 \\
\hline
\end{tabular}

Precision of temperature was $\pm 0.01^{\circ} \mathrm{C}$.

All the samples were analyzed by DSC (with the same method used previously for the raw hexadecane). From the obtained results, the quantitative data on melting and crystallization point as well as latent heat of fusion and crystallization of the hexadecane/pigment composites was extracted. Two aliquots of the processed samples were analyzed in order to assess the homogeneity of the obtained composites. Table 3 summarizes the prepared samples and the thermal properties obtained. 
Table 3. Thermal properties of hexadecane/pigment composites fabricated under different processing conditions.

\begin{tabular}{|c|c|c|c|c|c|c|c|c|c|}
\hline No. & $\begin{array}{c}\text { Ratio } \\
\text { pig:PCM }\end{array}$ & $\begin{array}{l}\text { Time } \\
\text { c (min) }\end{array}$ & $\begin{array}{l}\text { Time } \\
\mathrm{d}(\mathrm{min})\end{array}$ & $\begin{array}{l}\text { Time } \\
\text { e (min) }\end{array}$ & $\begin{array}{l}\text { Cleaning } \\
\text { strategy }\end{array}$ & $\begin{array}{c}\text { Melting } \\
\text { point }\left({ }^{\circ} \mathrm{C}\right)\end{array}$ & $\begin{array}{l}\text { Crystallization } \\
\text { point }\left({ }^{\circ} \mathrm{C}\right)\end{array}$ & $\begin{array}{l}\text { Latent heat } \\
\text { (fusion) (J/g) }\end{array}$ & $\begin{array}{c}\text { Latent heat } \\
\text { (Crystallization) } \\
(\mathrm{J} / \mathrm{g})\end{array}$ \\
\hline \multirow{2}{*}{1} & \multirow{2}{*}{ 1:0.8 } & \multirow{2}{*}{15} & \multirow{2}{*}{15} & \multirow{2}{*}{15} & \multirow{2}{*}{$\begin{array}{l}\text { Petroleum } \\
\text { ether }\end{array}$} & 18.47 & 13.98 & 44.62 & 45.25 \\
\hline & & & & & & 18.77 & 13.36 & 43.28 & 43.54 \\
\hline \multirow[t]{2}{*}{2} & \multirow[t]{2}{*}{ 1:0.8 } & \multirow[t]{2}{*}{30} & \multirow[t]{2}{*}{30} & \multirow[t]{2}{*}{30} & \multirow[t]{2}{*}{ Petroleum ether } & 18.36 & 13.24 & 23.75 & 23.87 \\
\hline & & & & & & 18.53 & 13.33 & 24.25 & 24.52 \\
\hline \multirow[b]{2}{*}{3} & \multirow[b]{2}{*}{ 1:0.8 } & \multirow[b]{2}{*}{60} & \multirow[b]{2}{*}{60} & \multirow[b]{2}{*}{60} & \multirow[b]{2}{*}{ Petroleum ether } & 18.6 & 13.32 & 25.96 & 22.4 \\
\hline & & & & & & 18.45 & 13.22 & 22.17 & 22.8 \\
\hline \multirow{2}{*}{4} & \multirow{2}{*}{$1: 1$} & \multirow{2}{*}{15} & \multirow{2}{*}{15} & \multirow{2}{*}{15} & \multirow{2}{*}{ Petroleum ether } & 18.05 & 12.87 & 24.33 & 24.43 \\
\hline & & & & & & 18.05 & 12.79 & 23.86 & 23.67 \\
\hline \multirow[b]{2}{*}{5} & \multirow[b]{2}{*}{$1: 1.5$} & \multirow[b]{2}{*}{15} & \multirow[b]{2}{*}{15} & \multirow[b]{2}{*}{15} & \multirow[b]{2}{*}{ Petroleum ether } & 17.99 & 12.52 & 21.54 & 21.89 \\
\hline & & & & & & 17.97 & 12.69 & 22.11 & 22.13 \\
\hline \multirow{2}{*}{6} & \multirow{2}{*}{ 1:0.8 } & \multirow{2}{*}{15} & \multirow{2}{*}{15} & \multirow{2}{*}{15} & \multirow{2}{*}{ Deionized water } & 18.2 & 13.23 & 30.34 & 30.17 \\
\hline & & & & & & 18.2 & 13.23 & 29.27 & 28.88 \\
\hline
\end{tabular}

The temperature accuracy of the DSC200F3 is $0.1 \mathrm{~K}$ and the enthalpy accuracy is below $1 \%$.

First three experiment set ups were oriented to optimize the different processing conditions for maximizing the composite thermal storage capability. For these experiments a fixed Ratio Pigment:Hexadecane (1:0.8) and a fixed cleaning strategy (washing with petroleum ether) were used applying different processing times. It was concluded that lowest processing times increase the obtained final latent heat. For this reason, for further experiments it was decided to fix the different processing times using the lowest ones (15 minutes for all of them).

A second series of experiments was defined to optimize the Ratio Pigment: Hexadecane with the final aim of maximizing the composite thermal storage capability. Fixed processing times and fixed cleaning strategy (washing with petroleum ether) were used applying different Ratio Pigment: Hexadecane. The Ratio Pigment: Hexadecane maximizing the latent heat is 1:0.8.

A third series of processing variables was defined to optimize the hexadecane/pigment composites cleaning strategy. Fixed processing times and fixed Ratio Pigment: Hexadecane (1:0.8) were used applying a different cleaning strategy consisting on a washing with deionized water. The cleaning strategy maximizing the latent heat is a washing with petroleum ether.

The maximum latent heat obtained for the Hexadecane/pigment composites fabricated by vacuum impregnation method (average) is $44.40 \mathrm{~J} / \mathrm{g}$ and was obtained using following process conditions: Ratio Pigment: Hexadecane of 1:0.8, a time having the pigment under vacuum of 15 minutes, the time having the mixture pigment-hexadecane under vacuum of 15 minutes, the time having the pigment-hexadecane mixture at atmospheric pressure of 15 minutes and using petroleum ether as the best cleaning strategy.

Aspect of the final composite and the standard ultramarine blue is shown in Figure 9.

The Differential Scanning Calorimetry Analysis of the composite having the highest latent heat is shown in Figure 10 compared to the analysis of the n-hexadecane.

\subsection{Final Composite Characterization}

The final composite was analyzed by an Leica DM2500 MH optical microscope equipped with a Leica DFC 295 CCD digital camera (Figure 11). Reflected light microscopy was utilized to study the macro-structure of final composite compared to the structure of the raw pigment. The sample was placed on a $7 \mathrm{~mm}$ quartz cover slip. Differences between un-modified and modified pigment are shown in Figure 11.

The particle size distribution of the hexadecane/pigment composite having the maximum latent heat was analyzed using a Malvern Mastersizer 2000 and the same conditions explained above. 


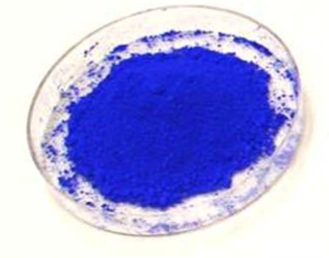

Standard ultramarine blue

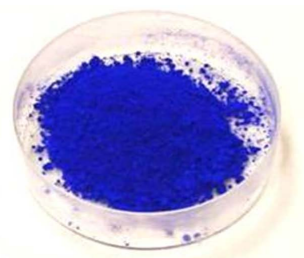

Sample 1 (final composite)

Figure 9. Standard ultramarine blue and final composite (having a latent heat of $44.40 \mathrm{~J} / \mathrm{g})$.

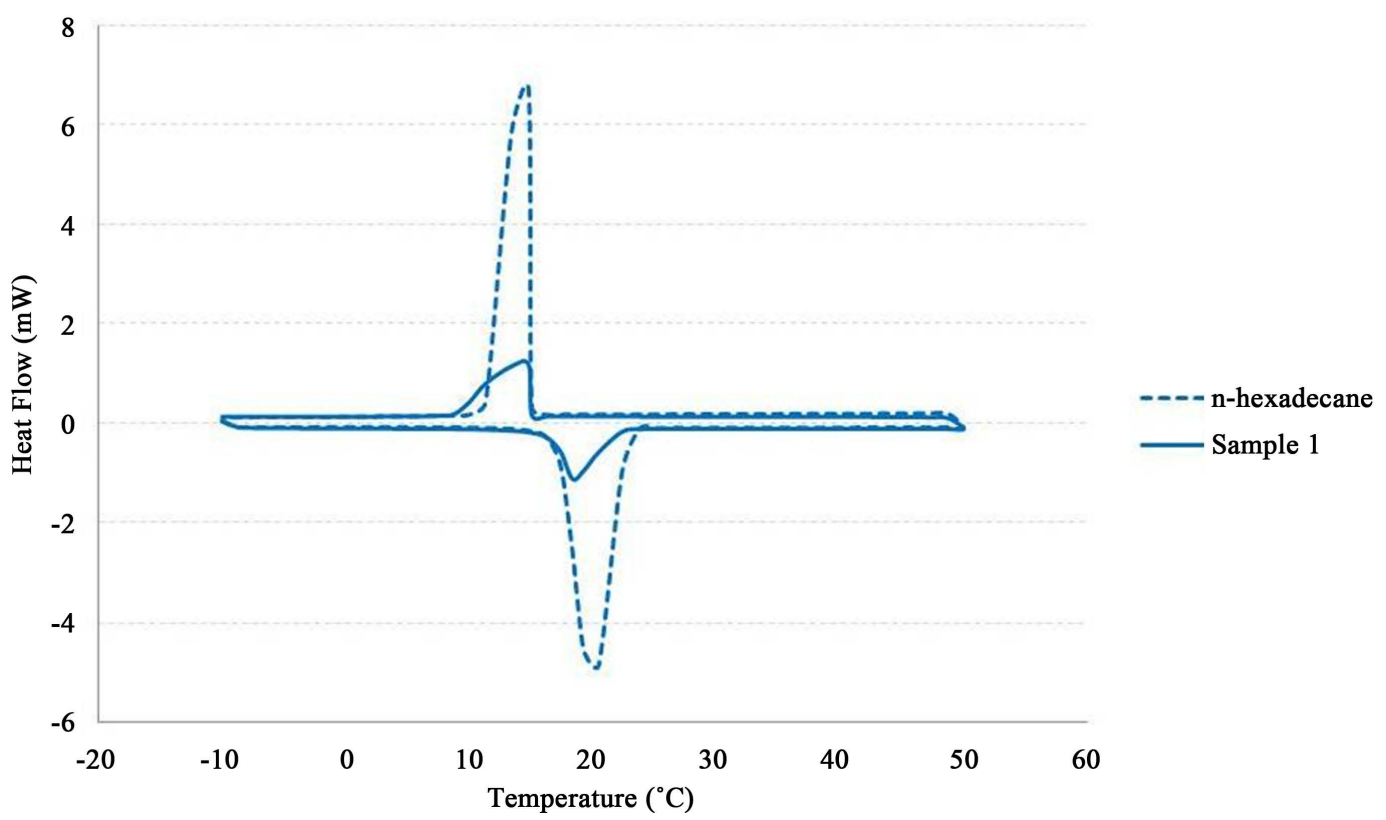

Figure 10. n-hexadecane and final composite Differential Scanning Calorimetry Analysis.
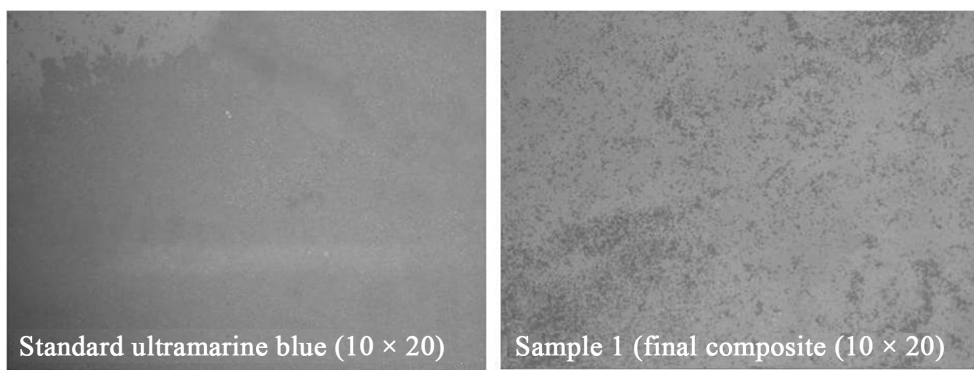

Figure 11. Optical micrographs of standard ultramarine blue and final composite.

Figure 12 shows the particle size distribution obtained. A stable and mono-modal distribution was obtained for this system being the mean particle size of $1.455 \mu \mathrm{m}$. An increase of $0.253 \mu \mathrm{m}$ is observed in the mean particle size due to the impregnation process when comparing the composite with the un-modified pigment.

The X-ray diffraction (XRD) patterns for the hexadecane/pigment composite were measured using a Bruker D8 Advance X-ray diffractometer. The powder patterns were recorded in $2 \theta$ steps of $0.033^{\circ}$ in the $5 \leq 2 \theta \leq 40$ range, counting for $0.8 \mathrm{~s}$ per step at $10^{\circ} \mathrm{C}$. Preliminary identification of the initial phases was evaluated using the original pigment and PCM as references; Sodalite (00-046-0103), Sodium Sulfide (00-003-0933), Sodium Hydrogen Sulfide (01-077-1883) and Hexadecane (00-030-1745). The observed XRD maxima are in good agreement with the compound mixture (Figure 13). 


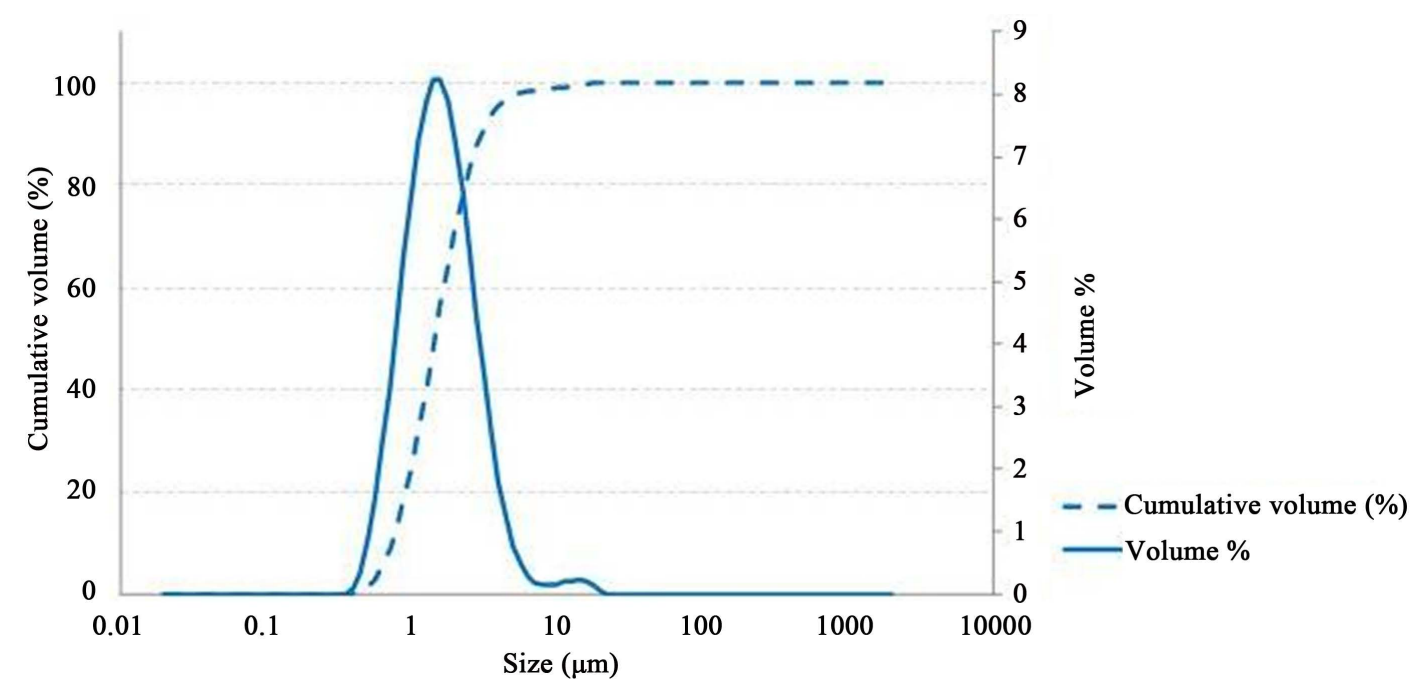

Figure 12. Particle size distribution of pigment/n-hexadecane composite having the highest latent heat.

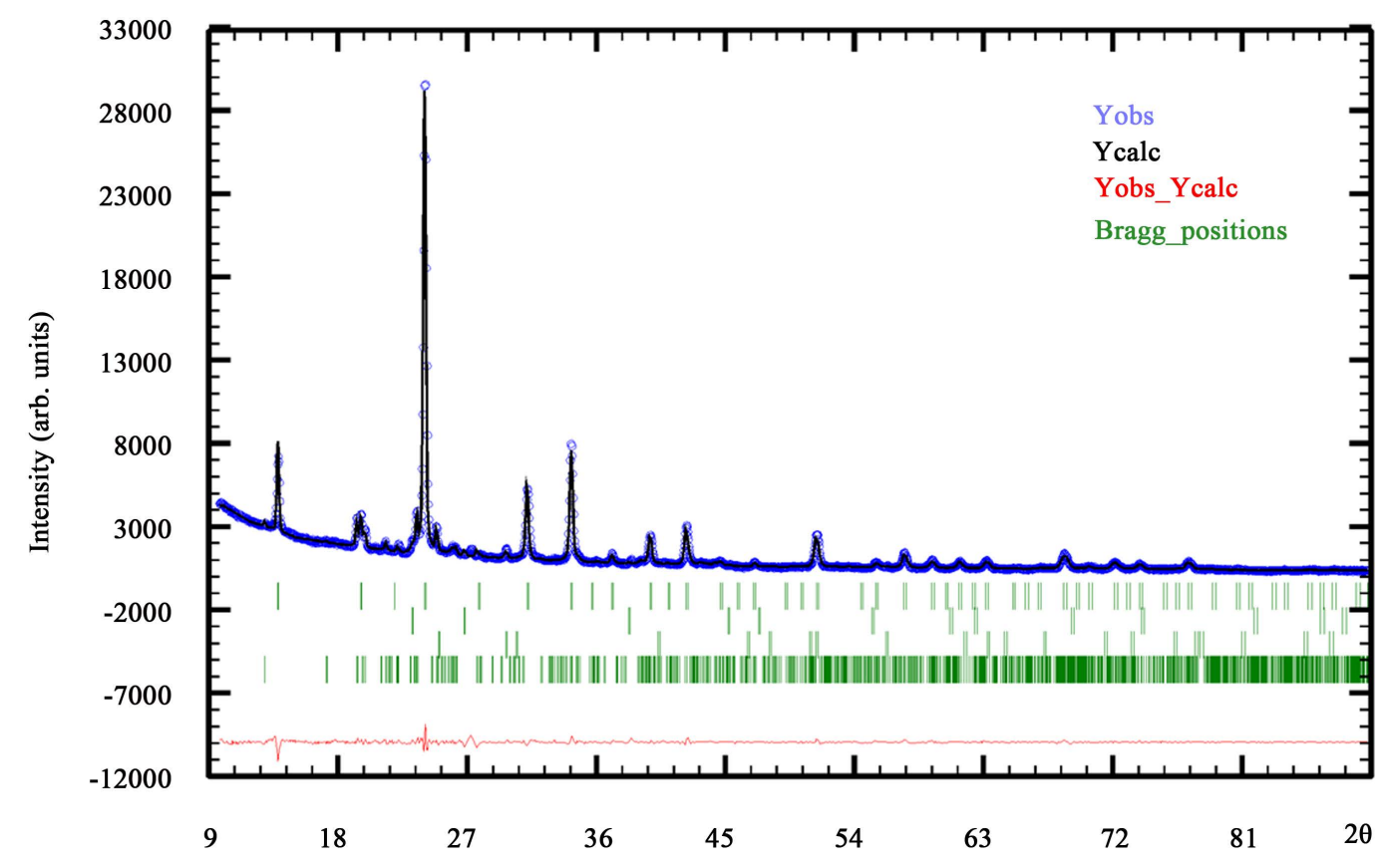

Figure 13. X-ray diffraction full profile refinement of Hexadecane/pigment composite. Circles denote experimental points; upper solid lines are calculated profiles. Theoretical peak positions (vertical sticks) and difference lines are shown in the bottom.

The semi quantitative calculations using the FULLPROF program for the main phases show the 18/82 relation for hexadecane/pigment composite.

\section{Materials Durability}

\subsection{Durability of the Final Composite at $30^{\circ} \mathrm{C}$}

The best composite obtained from vacuum impregnation process was subjected to $30^{\circ} \mathrm{C}$ during 1000 hours.

The latent heat of fusion and crystallization and the crystallization and melting points, were monitored at 250 hours, 500 hours, 750 hours and 1000 hours by using DSC technique (Table 4).

The results indicate slow reduction of the thermal storage capability up to $3 \%$ after the 1000 hours at $30^{\circ} \mathrm{C}$. 
Table 4. Thermal properties of the final hexadecane/pigment composites at different hours at $30^{\circ} \mathrm{C}$.

\begin{tabular}{ccccc}
\hline $\begin{array}{c}\text { Time at } 30^{\circ} \mathrm{C} \\
\text { (hours) }\end{array}$ & Melting point $\left({ }^{\circ} \mathrm{C}\right)$ & Crystallization point $\left({ }^{\circ} \mathrm{C}\right)$ & Latent heat (fusion) $(\mathrm{J} / \mathrm{g})$ & $\begin{array}{c}\text { Latent heat } \\
(\text { Crystallization })(\mathrm{J} / \mathrm{g})\end{array}$ \\
\hline 0 & 18.62 & 13.67 & 43.53 & 45.04 \\
250 & 18.81 & 13.62 & 44.02 & 45.61 \\
500 & 19.02 & 13.16 & 43.62 & 45.68 \\
750 & 18.85 & 13.02 & 43.74 & 44.08 \\
1000 & 18.68 & 13.43 & 42.26 & 44.04 \\
\hline
\end{tabular}

\subsection{Durability of the Composites against Cycling (Charge-Discharge of the Composites)}

One of the critical points for the incorporation of these kinds of composite materials in real construction was the knowledge of the degradation of the systems. The long time response of the composite was tested up to $1000 \mathrm{~h}$ at $30^{\circ} \mathrm{C}$. Nevertheless the temperature contrast must to be taking in to account if this composites are going to be used outside.

In order to simulate the heating and cooling processes associated with day and night conditions cyclic experiments were used. Given that the crystal signal of the PCM could be monitored by using X-ray diffraction, thermo-diffractometric measurements were done in a Bruker D8 Advance and an Anton Parr MRI low-temperature camera.

The powder patterns were recorded in $2 \theta$ steps of $0.033^{\circ}$ in the $18 \leq 2^{\circ} \leq 28$ range, counting for 2 s per step. Data sets were recorded at $4^{\circ} \mathrm{C}$ and $34^{\circ} \mathrm{C}$, with a $0.16^{\circ} \mathrm{C} \cdot \mathrm{s}^{-1}$ heating/cooling rate 100 times in static air conditions.

The obtained XRD results for the 100 cycles are shown in Figure 14.

The X-ray diffraction signals were evaluated by using the Diffrac Plus Evaluation EVA software. After extracting the background the raw area and half-width parameter of the (111) maxima of the PCM was calculated (Figure 15).

The results indicate slow reduction of the area intensity up to $6.5 \%$ after the 100 cycles. The obtained results were contrasted by DSC calculations for the final sample. The obtained fusion heat was in good agreement with the XRD data.

The reduction of the thermal storage capability was small enough (around 5\%) after 100 cycles to assume real live time of 10 years for this composite materials.

\section{Conclusions}

In this study, a form-stable phase change material composite based on ultramarine blue as the supporting matrix and n-hexadecane as the PCM was developed by using vacuum impregnation technique.

Different variables were optimized to obtain the highest latent heat. The maximum latent heat obtained for the hexadecane/pigment composites fabricated by vacuum impregnation method (average) is $44.40 \mathrm{~J} / \mathrm{g}$ and was obtained using following process conditions: Ratio Pigment: Hexadecane of 1:0.8, a time having the pigment under vacuum of 15 minutes, the time having the mixture pigment-hexadecane under vacuum of 15 minutes, the time having the pigment-hexadecane mixture at atmospheric pressure of 15 minutes and using petroleum ether as the best cleaning strategy.

A mono-modal distribution was obtained for this system being the mean particle size of $1.455 \mu$ m observing an increase of $0.253 \mu \mathrm{m}$ due to the impregnation process when comparing the composite with the un-modified pigment.

Continue temperature cycles of the material were tested by thermo-diffractometric measurements. The results indicate slow reduction of the area intensity of 6.5\% after 100 cooling/heating cycles. In the other hand the degradation of the thermal storage capability show a reduction of $3 \%$ after the 1000 hours at $30^{\circ} \mathrm{C}$. These results let us to conclude that the expected real live time for this composite material could be more than 10 years. 


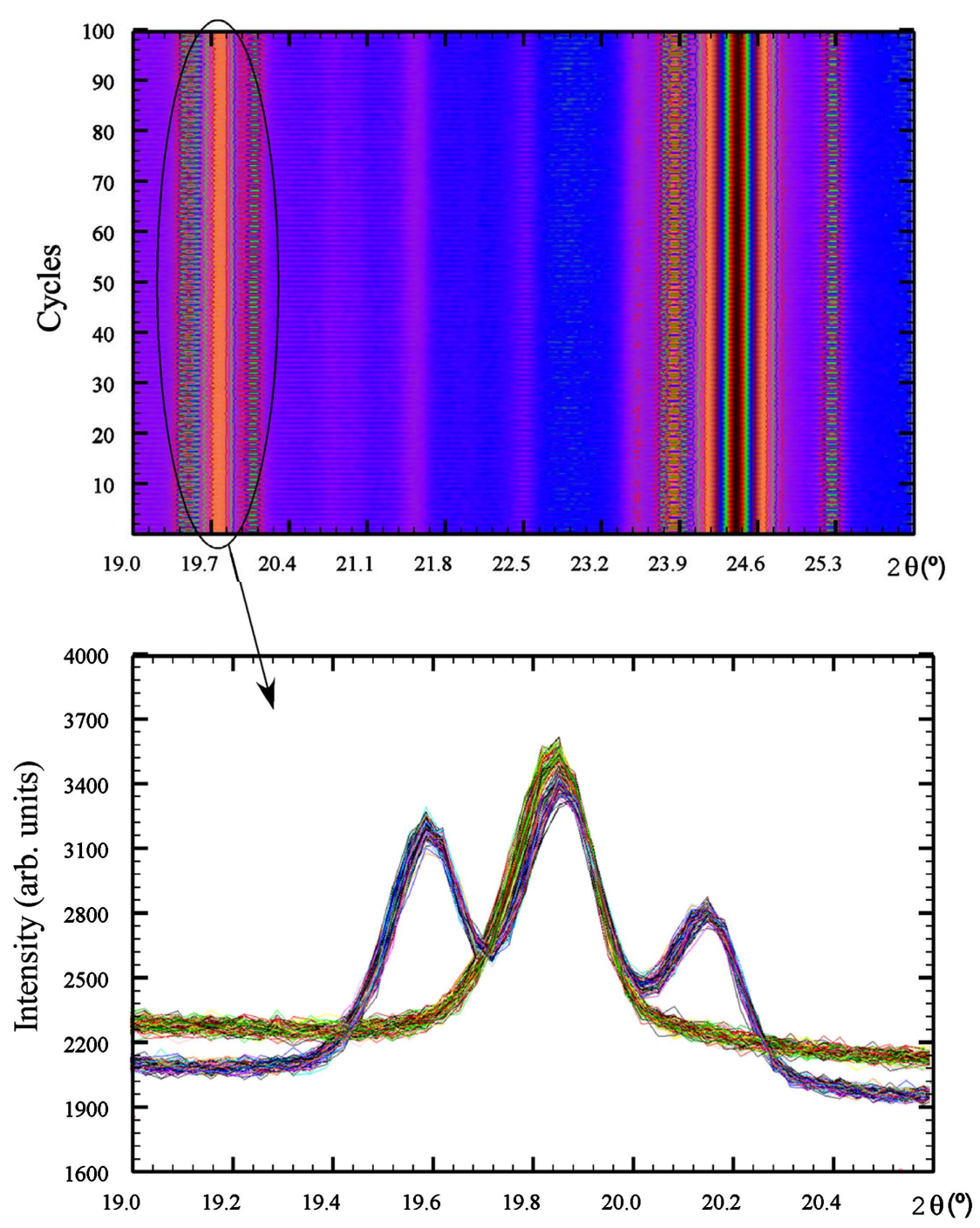

Figure 14. The $\mathrm{X}$-ray diffraction patterns for the composite changing the temperature from $2^{\circ} \mathrm{C}$ to $30^{\circ} \mathrm{C}, 100$ cycles.

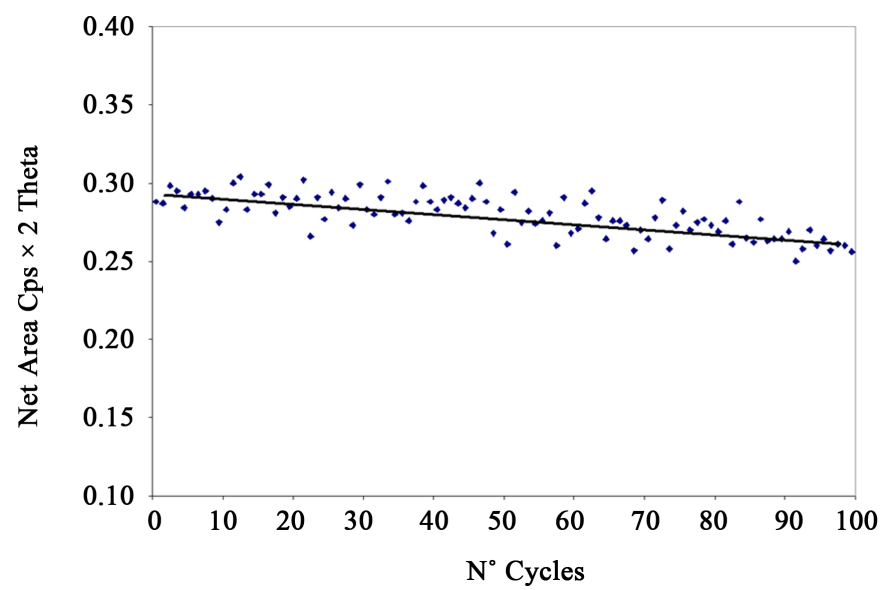

Figure 15. Evolution behavior for the X-ray diffraction intensity area of the (111) composite reflection. 


\section{Acknowledgements}

This project has received founding from the European Union Seventh Framework Programme (FP7-NMP-2010Small-5) under grant agreement ${ }^{\circ} 280393$ and from the Dpto. Educación, Política Lingüística y Cultura of the Basque Goverment (IT-630-13), Ministerio de Ciencia e Innovación (MAT2013-42092-R) and Engineering and Physical Sciences Research Council (EP/I003932). SGIker technical support (UPV/EHU, MEC, GV/EJ, European Social Fund) is gratefully acknowledged.

\section{References}

[1] Sharma, A., Tyagi, V.V., Chen, C.R. and Buddhi, D. (2009) Review on Thermal Energy Storage with Phase Change Materials and Applications. Renewable and Sustainable Energy Reviews, 13, 318-345. http://dx.doi.org/10.1016/j.rser.2007.10.005

[2] Faraji, M., Alami, M.E. and Najam, M. (2014) Thermal Control of Building Using Latent Heat Storage South Wall. Journal of Mathematics and Computer Science, 10, 212-227.

[3] Geetha, N.B. and Velraj, R. (2012) EEST Part A: Energy Science and Research, 29, 913-946.

[4] Chena, Y., Shiha, Y. and Yub, Y. (2013) Stearyl Alcohol Modified Expanded Graphite/Paraffin Phase Change Composite. International Journal of Applied Science and Engineering, 11, 227-233.

[5] Li, X.Y., Sanjayan, J.G. and Wilson, J.L. (2014) Fabrication and Stability of Form-Stable Diatomite/Paraffin Phase Change Material Composites. Energy and Buildings, 76, 284-294. http://dx.doi.org/10.1016/j.enbuild.2014.02.082

[6] Xu, B.W. and Li, Z.J. (2013) Paraffin/Diatomite Composite Phase Change Material Incorporated Cement-Based Composite For Thermal Energy Storage. Applied Energy, 105, 229-237. http://dx.doi.org/10.1016/j.apenergy.2013.01.005

[7] Sotomayor, M.E., Krupa, I., Várez, A. and Levenfeld, B. (2014) Thermal and Mechanical Characterization of Injection Moulded High Density Polyethylene/Paraffin Wax Blends as Phase Change Materials. Renewable Energy, 68, 140-145. http://dx.doi.org/10.1016/j.renene.2014.01.036

[8] Sun, Z.M., Zhang, Y.Z., Zheng, S.L., Park, Y. and Frost, R.L. (2013) Preparation and Thermal Energy Storage Properties of Paraffin/Calcined Diatomite Composites as Form-Stable Phase Change Materials. Thermochimica Acta, 558, 16-21. http://dx.doi.org/10.1016/j.tca.2013.02.005

[9] Zhou, D., Zhao , C.Y. and Tian, Y. (2012) Review on Thermal Energy Storage with Phase Change Materials (PCMs) in Building Applications. Applied Energy, 92, 593-605. http://dx.doi.org/10.1016/j.apenergy.2011.08.025

[10] Rodriguez-Ubinas, E., Ruiz-Valero, L., Vega, S. and Neila, J. (2012) Applications of Phase Change Material in highly Energy-Efficient Houses. Energy and Buildings, 50, 49-62. http://dx.doi.org/10.1016/j.enbuild.2012.03.018

[11] Jamekhorshid, A., Sadrameli, S.M. and Farid, M. (2014) A Review of Microencapsulation Methods of Phase Change Materials (PCMs) as a Thermal Energy Storage (TES) Medium. Renewable and Sustainable Energy Reviews, 31, 531542. http://dx.doi.org/10.1016/j.rser.2013.12.033

[12] Ma, Y.H., Sun, S.D., Li, J.Y. and Tang, G.Y. (2014) Preparation and Thermal Reliabilities of Microencapsulated Phase Change Materials with Binary Cores and Acrylate-Based Polymer Shells. Thermochimica Acta, 588, 38-46. http://dx.doi.org/10.1016/j.tca.2014.04.023

[13] He, F., Wang, X.D. and Wu, D.Z. (2014) New Approach for Sol-Gel Synthesis of Microencapsulated N-Octadecane Phase Change Material with Silica Wall Using Sodium Silicate Precursor. Energy, 67, 223-233. http://dx.doi.org/10.1016/j.energy.2013.11.088

[14] Nomura, T., Okinaka, N. and Akiyama, T. (2009) Impregnation of Porous Material with Phase Change Material for Thermal Energy Storage. Materials Chemistry and Physics, 115, 846-850. http://dx.doi.org/10.1016/j.matchemphys.2009.02.045

[15] Oy, T., Nomura, T., Okinaka, N. and Akiyama, T. (2013) Thermal Conductivity Enhancement of Erythritol as PCM by Using Graphite and Nickel Particles. Applied Thermal Engineering, 61, 825-828. http://dx.doi.org/10.1016/j.applthermaleng.2012.05.033

[16] Py, X., Olives, R. and Mauran, S. (2001) Paraffin/Porous-Graphite-Matrix Composite as a High and Constant Power Thermal Storage Material. International Journal of Heat and Mass Transfer, 44, 2727-2737. http://dx.doi.org/10.1016/S0017-9310(00)00309-4

[17] Memon, S., Lo, T.Y., Barbhuiya, S.A. and Xua, W.T. (2013) Development of Form-Stable Composite Phase Change Material by Incorporation of Dodecyl Alcohol into Ground Granulated Blast Furnace Slag. Energy and Buildings, 62, 360-367. http://dx.doi.org/10.1016/j.enbuild.2013.03.026

[18] Giraldo, C., Tobón, J.I. and Restrepo Baena, O.J. (2012) Ultramarine Blue Pigment: A Non-Conventional Pozzolan. Construction and Building Materials, 36, 305-310. http://dx.doi.org/10.1016/j.conbuildmat.2012.04.011 
[19] Fleet, M.E. and Liu, X. (2010) X-Ray Absorption Spectroscopy of Ultramarine Pigments: A New Analytical Method for the Polysulfide Radical Anion $\mathrm{S}_{3}$-Chromophore. Spectrochimica Acta Part B: Atomic Spectroscopy, 65, 75-79. http://dx.doi.org/10.1016/j.sab.2009.11.008

[20] Scherrer, P. (1918) Bestimmung, der Grosse und der inneren Struktur von Kolloidteilchen mittels Rontgenstrahlen. Nachrichten von der Gesellschaft der Wissenschaften zu Göttingen, 26, 98-100.

[21] Rietveld, H.M. (1969) A Profile Refinement Method for Nuclear and Magnetic Structures. Journal of Applied Crystallography, 2, 65-71. http://dx.doi.org/10.1107/S0021889869006558

[22] Rodríguez-Carvajal, J. (1993) Recent Advances in Magnetic Structure Determination by Neutron Powder Diffraction. Physica B: Condensed Matter, 192, 55-69. http://dx.doi.org/10.1016/0921-4526(93)90108-I

[23] Rodríguez-Carvajal, J. (2001) Recent Developments of the Program FULLPROF, in Commission on Powder Diffraction (IUCr). Newsletter, 26, 12-19. 